\title{
Roger de Comenge, Conde de Pallars, en el Archivo Ducal de Medinaceli (1229-1256) *
}

\author{
Pilar Ostos Salcedo **
}

Sobre los origenes del condado de Pallars, contamos con la ya clásica obra de Abadal ${ }^{1}$. En ella este autor precisa y aclara, cosa poco fácil, dichos inicios. A su vez, Valls Taberner marca y establece las genealogías de dichos condados durante los siglos XI, XII y primeros años del $\mathrm{XIII}^{2}$. Uno y otro son trabajos imprescindibles para la comprensión y conocimiento del discurrir histórico de este condado pirenáico ${ }^{3}$.

Ambas obras cubren, por consiguiente, la historia de este tradicional condado desde el siglo Ix hasta el año 1229, fecha en la que el segundo autor finaliza su estudio. No es ésta una data escogida al azar, sino que está plenamente fundamentada. El año 1229 significa para el condado pallarense la entrada de un nuevo linaje, el de los Comenge, procedente de la vertiente pirenáica francesa, que va a llevar las riendas del mismo hasta el final de esta centuria. El matrimonio que la heredera de Pallars, Sibilia, contrajo en 1297 con el noble Hugo de Mataplana tuvo como consecuencia la sustitución de un linaje por otro, ya que desde entonces la casa Mataplana dirigirá la vida pallaresa y ello hasta las postrimerías

* Comunicación presentada al I Congreso Internacional de Historia de los Pirineos. Cervera. Noviembre 1988.

** Universidad de Sevilla.

'Véase R. d'ABadal y Vinyals, "Els comtats de Pallars i Ribagorça», Catalunya Carolingia, Barcelona 1955.

2 Véase F. VALLS I TABeRneR, "Els origens dels comtats de Pallars i Ribagorça", recog en Obras Selectas, Barcelona 1952-1961, págs. 125-205.

${ }^{3}$ M. Ravina Martín realizó su Memoria de Licenciatura en 1973 sobre la documentación más antigua del condado de Pallars conservada en el Archivo Ducal de Medinaceli, desde el año 974 al 1229, desgraciadamente inédita. 
del condado, es decir, hasta que Fernando el Católico lo eleve a marquesado y se lo entregue al duque de Cardona -1491-.

No podemos tampoco silenciar la labor realizada por $F$. Llobet i Mas, prior de Meyà ${ }^{4}$, que en realidad fue el primer historiador del condado. $\mathrm{Su}$ labor quedó plasmada en varios manuscritos, conservados en la $\mathrm{Bi}$ blioteca de Cataluña, y, entre ellos, es fundamental el referido a la cronología de los condes y marqueses de Pallars, siendo también muy útil el que contiene la colección diplomática del monasterio de Santa María de Guerri ${ }^{5}$. Su obra ha servido de base para posteriores estudios, ya que la documentación conservada en el Archivo Ducal de Medinaceli (en adelante $A D M$ ) ha sido en general muy poco consultada ${ }^{6}$.

Valls Taberner, como hemos señalado, concluye su estudio cuando entra a gobernar el linaje de los Comenge, que se inicia con la donación y venta del condado de Pallars realizadas por la condesa Guillerma el 6 de marzo de 1229 al que fuera su segundo marido, Roger de Comenge ${ }^{7}$ :

«... ego Guillerma, comitissa Paliarensis, per me et per omnes meos dono tibi Rogerio Conuenarum, comiti Paliarensi, so totum comitatum Paliarensem ab integrum..." ${ }^{8}$.

«... ego Guillerma, comitissa Paliarensis, per me et per omnes meos uendo tibi Rogerio Conuenarum, comiti Paliarensi, totum comitatum Paliarensem ab integrum..." ${ }^{9}$.

Desde la fecha en que finaliza su trabajo Valls Taberner -1229hasta el final del condado -1491- no contamos con una monografía rigurosa y basada en documentación, si exceptuamos los estudios dedi-

4 Véase la semblanza que de él hizo S. SAMPERE I MIQUEL, «Los orígenes del condado de Pallars y su historiador fray Francisco Llobet i Mas", en Revista de Archivos, Bibliotecas y Museos, X, 1904, págs. 373:398.

5 Véase F. LlOBET I MAS, Cronología de los condes y marqueses de Pallars desde su erección hasta que sus estados pasaron a la casa de Cardona, ms. 425 de la Biblioteca de Cataluña, fols. 1-110v; Colección diplomática de Gerri, ms. 426 de la citada biblioteca.

${ }^{6}$ Sobre los fondos de Pallars en el ADM, véase, la reciente publicación de A. SÁNCHEZ GONZÁLEZ, “El archivo de los condes y marqueses de Pallars: Génesis, evolución y organización documental", en Collegats, I, 1987, págs. 162-176.

"ADM, sec. Pallars, leg. 1, docs. 19 y 20. Véase F. Valls TABERnER, "Els origens", págs. 196-197.

B ADM, sec. Pallars, leg. 1, doc. 20.

${ }^{9}$ ADM, sec. Pallars, leg. 1, doc. 19. 
cados a la guerra final que enfrentó al último conde, Hugo Roger (14511503), con el nuevo monarca. Una guerra que le llevó a la pérdida de sus territorios, a su permanencia en cautividad e incluso a una alianza con el monarca de allende los Pirineos ${ }^{10}$.

Más concretamente, las noticias del dominio Comenge en el condado de Pallars son escasas, inciertas, imprecisas y, en ocasiones, hasta contradictorias. Menciona Valls Taberner la escasez de noticias y de documentos existente para los primeros años del siglo XIII ${ }^{11}$ y señala a su vez Baucells la laguna que hay en la historia de este condado durante los siglos XIII y XIV ${ }^{12}$. Entre los fondos de la sección Pallars del ADM se nota paralelamente un descenso de documentación bastante notable para este período en relación con épocas anteriores y sobre todo posteriores. En general, la mayoria de los estudios publicados al respecto, y no son muchos, reiteran los datos sobre el mismo. Sin embargo, más recientemente Baucells ${ }^{13}$ y el malogrado Puig i Ferreté ${ }^{14}$ han presentado y defienden una nueva teoria de sucesión en el condado de Pallars al inicio del citado periodo Comenge.

La teoría tradicional, defendida, entre otros por Miret i Sans ${ }^{15}$ y sobre todo por Valls Taberner, recogida asimismo por Sobrequés ${ }^{16}$, considera que la condesa Guillerma, hija de Artal IV y de Guillerma, casó en primer matrimonio con el noble pallarés Guillermo de Erill y en segundas nupcias con el ultrapirenáico Roger de Comenge, II vizconde de Coserans. Desde 1217 hasta 1229 intitulan conjurtamente una serie, no numerosa, de documentos. En este último año, como hemos mencionado, la condesa titular vendió a su segundo marido, con el que tampoco tuvo

${ }^{10}$ La tumultuosa y agitada vida de este conde pallarés puede ser consultada en S. Sobrequés, Els barons de Catalunya, 4. ${ }^{a}$ ed., Barcelona 1980, págs. 187-199. Véase también A. Cor Cotonat, Sort y Comarca Noguera Pallaresa, Barcelona 1906, págs. 405-419. ALSINA DE LA TORRE, “El último conde de Pallars. Documentos inéditos", IX CHCA, 1973. M. Peláez Albendea, Hugo Roger III, último conde de Pallars (1436-1503), Tesis de Licenciatura, Universidad de Barcelona, 1974. A. RiBA I PALAU, La fi del comtat de Pallars, Barcelona 1923.

1 Véase, F. Valls TABerner, "Els origens", pág. 194.

12 Véase, J. Baucells I ReIG, "La successió dels comtes de Pallars en el Dos-cents", en X CHCA, II, Zaragoza 1982, pág. 21.

${ }^{13}$ Ibidem.

14 Véase, 1. Puig I Ferreté, “Testaments comtals del Pallars Sobirà. La casa Comenge (1256-1327)", en Urgellia, IV, 1981, págs. 293-333.

15 Véase, J. MiREt I SANS, "La princesa griega Lascaris, condesa de Pallars en Cataluña", en Revue Hispanique, X, 1903, págs. 455-470.

16 Véase, S. Sobrequés, Els barons, págs. 95-96. 
descendencia, el condado de Pallars por la cantidad de 15.000 maravedíes de oro, venta que fue repetida el 7 de noviembre de $1231^{17}$. El mismo día, mes y año de la donación y venta del condado, Roger de Comenge reconoce deber a su mujer Guillerma la cantidad de 4.000 maravedíes y promete pagarle 1.000 maravedies en Pentecostés y los 3.000 restantes en Navidad. Guillerma le promete la entrega del condado cuando haya satisfecho su deuda y éste se compromete a custodiar y defender todo el territorio del condado pallarense ${ }^{18}$.

Poco tiempo después, la condesa se retiraría al monasterio cisterciense de Vallbona, donde parece que vivió hasta mediados de esta centuria.

A partir del año 1235, Roger de Comenge aparece casado con Sibilia de Saga, también llamada de Berga, de cuyo enlace nacerían los dos futuros titulares del condado: Arnaldo Roger y Ramón Roger, además de dos hijas: Orpaix que se casó con Pedro, vizconde de Vilamur ${ }^{19}$, y Geralda que lo hizo con Guillermo de Bellera.

Sin embargo Baucells ${ }^{20}$ y Puig ${ }^{21}$ basados en los manuscritos recopilados por F. Llobet i Mas, así como en las obras de Zurita ${ }^{22}$ y Marca ${ }^{23}$, exponen una teoría diferente a la anterior.

Estos autores distinguen dos condes de nombre Roger, padre e hijo. Uno, Roger I sería efectivamente marido de Guillerma de Pallars, al que vendiera dicho condado. El otro, Roger II, sería hijo del anterior, tenido antes de su matrimonio con Guillerma, y marido de Sibilia de Saga, de cuya unión matrimonial nacerían los futuros Arnaldo Roger I y Ramón Roger I.

Siguiendo a Baucells y a Puig, en 1234 Roger I donó el condado de Pallars a su hijo Roger II tras su casamiento con Sibilia. El último docu-

17 ADM, sec. Pallars, leg. 1, doc. núm. 22.

${ }^{18}$ ADM, sec. Pallars, leg. 1, doc. núm. 21. Véase, también J. BauCELLS, "La successió", pág. 27.

19 Pedro de Vilamur, no Ramón como aparece en muchas ocasiones.

20 Véase, J. Baucells, “La successió", págs. 26 y ss.

21 Véase, I. Puig I Ferreté, «Testaments», págs. 295-298.

22 Véase, J. ZurITA, Anales de la Corona de Aragón, Lib. V, cap. XXVII, editado por A. CANELLAS LOPEZ, Zaragoza 1970, págs. 525-526.

${ }_{23}$ Véase, P. MARCA, Histoire de Bearn, Paris 1640, pág. 790. 
mento en el que constatan su presencia data de $1240^{24}$, desconociéndose la fecha de su fallecimiento. Desde entonces hasta 1256, el gobierno del condado estaría en manos de Roger II. tada?

Ante esta dualidad de opiniones, ¿qué teoría nos parece la acer-

Analizando minuciosamente la documentación existente en el ADM sobre los primeros años de Comenge e, igualmente, las noticias recopiladas por B. J. Llobet ${ }^{25}$, creemos que no se puede hablar de Roger I y Roger II, sino que nos encontramos ante un único noble francés que casó dos veces con sendas damas catalanas -Guillerma de Pallars y Sibilia de Berga-.

La fundamentación de esta afirmación la podemos encontrar en un documento otorgado pocos meses antes de su testamento, cuando Roger de Comenge, conde de Pallars, el 16 de mayo de 1256 instituye como heredero a su hijo Arnaldo Roger y le entrega el condado de Pallars ${ }^{26}$ con todos sus castillos, villas y pertenencias, prometiendo no revocar esta donación. Casi al final del documento se incluye el siguiente párrafo:

"Omnia uero supradicta et singula damus et concedimus ac in presenti tradimus uobis Arnaldo Rogerii, filio nostro, et uestris, sicut nos melius habuimus et emimus et accaptauimus a domna Guillerma, condam uxore nostra et comitissa Pallariense et donata Vallebone» ${ }^{27}$.

Según éste, se desprende de forma clara y fuera de toda duda que el padre de Arnaldo Roger I fue el mismo Roger de Comenge que había sido marido de la condesa Guillerma, señalando además que el condado to había adquirido mediante compraventa.

A las mismas conclusiones llega el archivero B. J. Llobet en su Inventario de Pallars tras realizar el extracto de los documentos núms. 27

${ }^{24}$ Baucells considera que en las suscripciones de un documento de 12 de julio de 1240, Roger I lo hace sin mencionar su título condal y al lado de su hijo y nuera Sibilia, no compartimos estas atribuciones, más bien pensamos que es Roger I el que se autotitula conde de Pallars, la condesa Sibilia su mujer y, por último, el hijo del primero (Véase, J. BaUCELls, "La successió", pág. 31, núm. 31).

${ }^{25}$ Véase, B. J. LLOBET, Recopilación e Inventario de los autores y otras escrituras del Marqués de Pallars, Falset, 1662.

${ }^{26}$ ADM, sec. Pallars, leg. 1, doc. 27.

${ }^{27}$ Ibidem. 
y 28 de esta sección, expresándose de la siguiente manera: "refiere dicho Roger de Comenge, conde de Pallars, en la dicha donación que doña Guillerma, condesa de Pallars, hauia sido su muger, de donde se infiere que hauia tenido dos mugeres que fue ella y dicha condesa doña Sibilia» ${ }^{28}$.

Tres meses más tarde, el 21 de agosto de 1256 Roger de Comenge ordena su testamento ${ }^{29}$ y reitera sus disposiciones anteriores, haciendo heredero del condado de Pallars, de la villa de S. Girons y de las restantes villas que posee en la diócesis de Coserans a su hijo legítimo Arnaldo Roger. Al final del mismo, revoca todas las donaciones que hubiera efectuado a su hijo ilegítimo Roger porque «manu armata et cum plures militibus et hominibus armatis" habia ido contra su padre y contra todo el condado ${ }^{30}$. en este documento asimismo se indica de forma clara que este Roger de Comenge había nacido de su unión ilícita con Cecilia, condesa de Forcalquer:

«Rogerius Conuenarum, qui filius noster est, dictus fuerit genitus et natus ex nobis et domna Cecilia, matre sua, viuente comite Fontis Cauquerii, marito ipsius domne Cecilie, et ita ex dampnato et illicito coitu genitus et natus fuerit idem Rogerius ex nobis et domna Cecilia supradicta»" ${ }^{31}$.

Con ambos documentos, expedidos en un plazo de tres meses de diferencia, el conde de Pallars, Roger de Comenge, nos desvela los interrogantes que sobre su figura se han generado. Por una parte, que él fue el segundo marido de la condesa Guillerma, a la que compró el condado de Pallars y después donó repetidas veces a su hijo Arnaldo Roger. De oira, que su hijo Roger de Comenge habia sido fruto de sus relaciones extramatrimoniales con la condesa ultrapirenaica Cecilia de Forcalquer y ello, como se señala en otros documentos, antes de $1236^{32}$.

${ }^{28}$ Cfr. B. J. Llobet, Recopilación, fol. 49r.

${ }^{29}$ 1. Puig señala que no ha podido localizar este documento, por lo que sólo pudo servirse del extracto recogido por B. J. LLOBET en su Inventario (véase, I. PUIG I FERRETE, "Testaments", págs. 303 y 320). J. Baucells sigue la copia que del mismo hizo F. Llobet i Mas (véase J. BAUCELLS, "La successió", págs. 32-33.

${ }^{30} A D M$, sec. Pallars, leg. 1, doc. núm. 30.

${ }^{31}$ lbidem.

${ }^{32} A D M$, sec. Pallars, leg. 1, doc. núm. 23. 
Con ello, creemos, queda despejada la cuestión sobre la existencia o no de dos condes del mismo nombre, Roger I y Roger II, ya que éste no existió en realidad, sino que Roger I prolongó su gobierno hasta 1256, fecha en la que otorga su testamento y lega el condado de Pallars a los hijos procreados de su matrimonio con Sibilia de Berga.

Los documentos que se conservan en el ADM del primer Comenge son escasos y de temática poco variada. Aparte de la donación y venta del condado de Pallars del año 1229, repetida esta última en 1231, que ya hemos mencionado, en marzo de 1236 Roger de Comenge aparece casado con Sibilia, hija de Bernardo de Saga, y debía ser reciente su matrimonio, porque en dicha fecha hace donación del condado a una futura descendencia que naciera de dicho enlace y en caso negativo éste pasaría a su hijo Roger de Comenge, que corrobora personalmente dicha donación ${ }^{33}$. Esta condesa Sibilia consta como fallecida a principios de 1253: “...Geralda, predicta uxore tua, filia domini Rogerii de Comenge, comitis Palariensis, et uxoris quondam sue domina Sebilia et sororis Petri de Berga..." ${ }^{34}$.

Un año antes -1235--, Roger de Comenge protagoniza una concordia con Pedro, vizconde de Vilamur, para poner fin a una guerra existente entre ambos y constituirse en "amicum uestrum de uera amicitia” ${ }^{35}$. Quizás consecuencia de esta concordia, sea el doble pacto matrimonial realizado en 1242 entre Roger y Sibilia, condes de Pallars, de una parte y Pedro y Sancha Pérez, vizcondes de Vilamur, de otra ${ }^{36}$. Acuerdan el enlace entre el primogénito de Pallars - Arnaldo- y Sancha Pérez y el de Orpaix, hija de los condes, con el heredero de Vilamur, Pedro. Este pacto fue confirmado más tarde en 1250 por Roger de Comenge al vizconde de Vilamur, reiterando de nuevo y de forma explícita el doble matrimonio acordado ${ }^{37}$. Cuatro años después entrega su hijo Arnaldo a Pedro de Vilamur y asimismo varios castillos como seguridad para el cumplimiento de dicho pacto matrimonial ${ }^{38}$.

${ }^{33}$ ADM, sec. Pallars, leg. 1, doc. núm. 23. A. CoY Cotonat, Sort cita el contenido de este documento sin señalar su fecha. I. PUIG I FerRETE, "Testaments", lo atribuye al año 1235, quizás al no tener en consideración que la expresión de la data utiliza el estilo de la Encarnación. J. BAuCELls, "La successió" lo fecha, sin embargo, en 1236.

${ }^{34}$ ADM, sec. Pallars, leg. 16, doc. núm. 901.

35 Véase P. Ostos SALCEDO, "Documentación del Vizcondado de Vilamur en el Archivo Ducal de Medinaceli (1126-1301)", en HID, 8, Sevilla 1982, doc. núm. 20, págs. 342-342.

36 Ibidem, doc. núm. 24, págs. 347-349.

${ }^{37}$ ADM, sec. Pallars, leg. 1, doc. núm. 25. Véase A. Coy Cотомat, Sort, pág. 303.

${ }^{38}$ ADM, sec. Pallars, leg. 1, doc. núm. 26. Véase A. Cor Cotonat, Sort, págs. 318-319. 
Cuando se acuerda el casamiento de Arnaldo Roger, éste no podía contar con más de 6 años de edad, ya que en 1236 no existía todavía descendencia de Roger de Comenge y Sibilia de Berga ${ }^{39}$. Su minoría de edad y la de los otros contrayentes queda reflejada en dicho pacto: «Et omnia hec predicta atendemus et atendi faciamus cum predicti filii nostri et uestri perueniunt ad etatem legitimam matrimonii contrahendi» ${ }^{40}$. Al confirmarse este pacto en 1250 , no sobrepasaba los 14 años y cuando hereda el condado seis años después, los 20.

En 1244, ya habian nacido todos los hijos legítimos de los condes de Pallars. En diciembre de este año, Roger de Comenge dona todo el condado de Pallars a su hijo Arnaldo Roger ${ }^{41}$. Expresa el deseo de que su segundo hijo varón, Ramón Roger, sea eclesiástico y le otorga una dote de 1.000 maravedies. A su hija Orpaix le asigna 3.000 maravedies y a Geralda 2.500 maravedíes. Como en otros documentos, establece la línea sucesoria a seguir si sus hijos fallecieran sin descendencia legítima y señala en primer lugar que sea Ramón Roger, si no hubiera entrado en religión, el que suceda a su hermano, después Orpaix y, finalmente, Geralda. Como señalara ocho años antes ${ }^{42}$, si estos cuatro hijos no tuvieran descendencia, el condado de Pallars debería pasar a su hijo Roger de Comenge.

Además de estos hijos mencionados, los documentos nos informan de la existencia de otros tres, que suponemos fueron ilegítimos. Tan sólo conocemos sus nombres al ser receptores de determinadas donaciones. En 1253, Roger de Comenge dona a su hijo Ramón de Peramea el castillo y villa de Montformit, donación que fue corroborada también por su hijo Arnaldo Roger: "dono et concedo et personaliter trado tibi Raimundo de Peramedia, filio meo, castrum et villam de Montformit» ${ }^{43}$. Años más tarde, en 1276, Arnaldo Roger, conde, entrega a su hermano Bernardo de Comenge el castillo de Llort y le asigna la cantidad anual de 200 sueldos situados en la villa de Obac ${ }^{44}$. El mismo Bernardo de Co-

39 $A D M$, sec. Pallars, leg. 1, doc. núm. 23.

40 Cfr. P. Ostos SALCEDO, «Documentación de Vilamur», doc. núm. 24, pág. 347.

${ }^{11} A D M$, sec. Pallars, leg. 1, doc. núm. 24. Véase J. Baucells, "La successió", págs. 31-32.

${ }^{42}$ ADM, sec. Pallars, leg. 1, doc. núm. 23.

${ }^{43} A D M$, sec. Pallars, leg. 17, doc. núm. 1.044. Cabría la posibilidad de que éste sea Ramón Roger, aunque en otros documentos siempre completa su nombre con el de Roger, al igual que harán en un futuro todos los herederos del condado de Pallars, a pesar de la extinción de la casa Comenge y su sustitución por la de Mataplana.

${ }^{44}$ ADM, sec. Pallars, leg. 19, doc. núm. 1.203. 
menge y otro hermano llamado Comenges fueron designados albaceas testamentarios por Arnaldo Roger, recibiendo cada uno un legado de 300 sueldos de por vida ${ }^{45}$.

Como titular del condado, Roger de Comenge en 1242 ordenó a los habitantes de Salàs que permanecieran en paz y en caso de homicidio estableció que el autor del mismo vería incautados todos sus bienes y perdería la vida "omnen honorem et pecuniam illius homicide uel illorum homiciduum in posse nostro uel successorum nostrorum incurrantur " ${ }^{46}$. En 1247 otorgó carta de franquicia a los habitantes de Llavorsi ${ }^{47}$.

En sus relaciones con otros caballeros y nobles del condado, además de la concordia y pacto matrimonial establecidos con Pedro, vizconde de Vilamur, que ya hemos señalado, casa a su segunda hija, Geralda, con Guillermo de Erill, hijo de Guillermo de Bellera y Arsenda ${ }^{48}$. También este matrimonio pudo ser fruto de las tentativas de acuerdo con la familia Bellera, ya que en otros documentos anteriores tanto Roger de Comenge como Ramón de Bellera eligen árbitros para que diriman sus diferencias en torno a las potestades de ciertos castillos. El conde de Pallars designa a Pedro de Berga y Ramón de Bellera a Pedro Isern ${ }^{49}$. Del mismo modo, en 1249 reclama a Bertrán de Aramunt la potestad de otro castillo, sin especificar su nombre, recordándole su derecho a dicha demanda ${ }^{50}$.

Por otra parte, en 1247 Roger de Comenge entrega en prenda a Guillermo de Orcau la batllía del castillo de Aramunt y la mitad de la renta del horno de Salàs como garantía de pago de los 270 sueldos que le había prestado ${ }^{51}$. Finalmente, dona a Pedro Isern de Aron, a su mujer

${ }^{45} A D M$, sec. Pallars, leg. 1, doc. núm. 38. Véase I. Puig I Ferrete, "Testaments", pág. 320-324.

${ }^{46} A D M$, sec. Pallars, leg. 14, doc. núm. 739. Véase A. Cor Cotonat, Sort, pág. 72.

${ }^{47} A D M$, sec. Pallars, leg. 9, doc. núm. 340.

${ }^{48}$ El 22 de enero de 1253, Guillermo de Bellera y su mujer Arsenda entregan a su hijo Guillermo de Erill todas sus posesiones situadas en el valle de Assua, como Surb y Torena, el castillo de Erill, la mitad del valle de Boi, entre otras. (Véase $A D M$, sec. Pallars, leg. 16, doc. núm. 901).

${ }^{49} A D M$, sec. Pallars, leg. 16, doc. núm. 910. Este documento carece de data. Precisamente, en la sentencia promulgada el 1 de diciembre de 1221 sobre el litigio por el honor de Bellera entre Ramón Guillermo, tío de Jaime I, y Guillermo de Bellera, intervino Roger de Comenge en su nombre y en el de la condesa Guillerma, para defender a Guillermo de Bellera. (Véase $A D M$, sec. Pallars, leg. 16, doc. núm. 900).

${ }^{50} A D M$, sec. Pallars, leg. 19, doc. núm. 1.187.

${ }^{51} A D M$, sec. Pallars, leg. 20, doc. 1.264. Precisamente Guillermo de Orcau y todos los 
María y a sus hijos «illud podium quod uocatur Penacuta», situado entre Estaron y Aidi, para su edificación y defensa ${ }^{52}$.

Las últimas disposiciones promulgadas por este citado conde están directamente relacionadas con su sucesión en el condado de Pallars y datan del mismo año -1256-, ya hemos hecho referencia a ellas.

En primer lugar, el 15 de mayo de este citado año entrega el condado de Pallars e instituye como heredero a su hijo Arnaldo Roger, a la vez que ruega y manda a todos los nobles y caballeros del condado, enumerándolos personalmente, que le sean fieles:

“Nos, gratia Dei, Rogerius Conuerarum, comte Paleirensis, per bona voluntate et in mea bona memoria dono et concedo et heredito et in presenti trado omni comitatu nostro Palearensis toto ab integrum cum omnibus eius pertinenciis a tibi, filio noster, Arnaldo Roger et rogo et mando ad omnes nostros nobiles, viros, milites..." ${ }^{53}$.

Un dia más tarde, en otro documento instituye nuevamente como heredero del citado condado al primogénito de los legítimos, haciendo una prolija descripción del mismo, pero retiene para sí el usufructo «nichil in tota uita nostra nisi usufructuum retenemus" ${ }^{54}$. En las cláusulas de sustitución establece el mismo orden que ya señalara en $1244{ }^{55}$ y después en su testamento, aunque ya en esta fecha no menciona el deseo de que su hijo Ramón Roger fuera eclesiástico. Idéntico contenido presenta el documento de 19 de mayo de $1256^{56}$.

Su testamento data finalmente del 21 de agosto de $1256^{57}$. En él, Roger de Comenge estando sano y en su perfecta memoria, tal y como señala en el expositivo, "testamentum nostrum facimus" y enumera una serie de legados. En primer lugar establece que sea repartida la cantidad

habitantes de Salàs prestaron homenaje a Pedro vizconde de Vilamur, que actúa en nombre de Roger de Comenge y de su hijo Arnaldo Roger el 2 de febrero de 1255 (vease, $A D M$, sec. Pallars, leg. 14, doc. 737).

52 ADM, sec. Pallars, leg. 18, doc. 1.099.

${ }_{53}$ ADM, sec. Pallars, leg. 1, doc. 29. Véase, A. Coy Cotonat, Sort, pág. 303.

${ }^{54} A D M$, sec. Pallars, leg. 1, doc. 27.

${ }^{55} A D M$, sec. Pallars, leg. 1, doc. 24.

${ }^{56} A D M$, sec. Pallars, leg. 1, doc. 28. Véase, también I. Puig I Ferrete, "Testaments", pág. 297.

${ }^{57} A D M$, sec. Pallars, leg. 1, doc. 30. Véase, J. Baucells, "La successió", págs. 32-33. 
de 10.000 sueldos entre pobres, personas indigentes y lugares píos para remedio de su alma. A continuación, determina que sus herederos salden todas sus deudas, pero sin especificar tales deudas.

Respecto a su heredero legítimo reitera lo ya establecido en documentos anteriores, aunque añade que Arnaldo Roger sea su sucesor no sólo en el condado de Pallars, sino también en la villa de S. Girons y en las restantes posesiones de la diócesis de Coserans. Lo mismo ocurriría si accediese a la titularidad del condado Ramón Roger. Ahora bien, si ambos muriesen sin descendencia legítima, S. Girons y otras posesiones de Coserans deberian pasar a su primo Bernardo, conde de Comenge, mientras que el Pallars pasaria a sus hijas: Orpaix, primero y Geralda, después. Sólo si éstas fallecieran sin descendencia, el condado de $\mathrm{Pa}$ llars sería detentado por su hijo ilegítimo Roger de Comenge. Es aquí, como mencionamos anteriormente, donde deja constancia de las circunstancias de su nacimiento $y$, asimismo, donde a pesar de su posible sucesión, revoca todas las donaciones realizadas con anterioridad por el levantamiento que había protagonizado contra su padre ${ }^{58}$.

Ésta es, en líneas generales, la trayectoria de un noble francés que enraizó en tierras catalanas tras sus dos matrimonios y que contribuyó, señala Sobrequés, a asegurar la catalanización de la nueva casa condal pallaresa ${ }^{59}$ durante los años que dirigió el condado de Pallars, es decir, desde 1229 hasta $1256{ }^{60}$. A partir de 1260 los documentos de Pallars están intitulados por su hijo Arnaldo Roger y ello hasta 1288.

58 Roger de Comenge va a pretender en todo momento acceder al condado. Tanto él como el hijo nacido de su matrimonio con Grisa de España, Arnaldo de España, van a plantear serios problemas en el condado de Pallars y lo van a invadir repetidas veces, especialmente tras la muerte de Arnaldo Roger I y de Ramón Roger I al hacerse cargo del condado Sibilia, hija del primero. En 1260 Arnaldo de España realiza una concordia con su tío Arnaldo Roger I, conde de Pallars (véase ADM, sec. Pallars, leg. 1, doc. 32) y en 1262 Gastón, vizconde de Bearn, y Ramón, vizconde de Cardona, como árbitros sentencian que el condado de Pallars pertenezca por herencia paterna a Arnaldo Roger I y a su hermano Ramón Roger I, y el vizcondado de Coserans corresponda a Arnaldo de España. los tres aprueban dicha sentencia (véase $A D M$, sec. Pallars, leg. 1, doc. 33).

59 Véase S. SOBREQuES, Els barons, pág. 96.

60 1256, no 1267 como señala Sobrequés (Ibidem). 


\section{APÉNDICE DOCUMENTAL}

6 de marzo de 1229.

Guillerma, condesa de Pallars, dona a Roger de Comenge, conde de Pallars, el condado de Pallars.

Pergamino de $271 \times 100 \mathrm{~mm}$. Buen estado de conservación. Tinta ocre. Escritura carolina.

ADM, sec. Pallars, leg. 1, doc. 20.

II

6 de marzo de 1229.

Guillerma, condesa de Paliars, vende a Roger de Comenge, conde de Pallars, el condado de Pallars por 15.000 maravedies de oro.

Pergamino de $260 \times 170 \mathrm{~mm}$. Buen estado de conservación. Tinta ocre. Escritura carolina.

ADM, sec. Pallars, leg. 1, doc. 19. Ripoll.

Copia certificada de 1328 , octubre 14 , efectuada por Pedro Redonell notario de

Edit. F. Valls Taberner, Els comtats, págs. 196-197.

ADM, sec. Pallars, leg. 1, doc. 19. 
Roger de Comenge, conde de Pallars, en el archivo ducal de Medinaceli

III

6 de marzo de 1229.

Roger de Comenge, conde de Pallars, promete pagar a su mujer Guillerma los 4.000 maravedies que le debe.

Pergamino de $217 \times 85 \mathrm{~mm}$. Buen estado de conservación. Tinta ocre. Escritura carolina. Carta partida por ABC. Se conservan los dos originales.

ADM, sec. Pallars, leg. 1, doc. 21.

IV

7 de noviembre de 1231 .

Guillerma, condesa de Pallars, vende a su marido Roger de Comenge, conde de Pallars, el condado de Pallars.

Pergamino de $240 \times 273 \mathrm{~mm}$. Buen estado de conservación. Tinta ocre. Escritura carolina. Carta partida por $A B C$.

ADM, sec. Pailars, leg. 1, doc. 22.

Copia certificada de 1320 , junio 7 , efectuada por Ramón de Castell notario de Mataplana.

ADM, sec. Pallars, leg. 1, doc. 22. Ripoll.

Copia certificada de 1328 , octubre 15 , efectuada por Pedro Redonell, notario de

ADM, sec. Pallars, leg. 1, doc. 22.

Copia simple del siglo xVIII.

ADM, sec. Pallars, leg. 1, doc. 22. 


\section{V}

6 de marzo de 1236.

Roger de Comenge, conde de Pallars, dona a todos los hijos que nazcan de su matrimonio con Sibilia, hija de Bernardo de Saga, el condado de Pallars.

Copia certificada de 1248, julio 26 , efectuada por Arnaldo Bergues, scriptor público de Berga. Pergamino de $219 \times 160 \mathrm{~mm}$. Buen estado de conservación. Tinta ocre. Escritura gótica.

ADM, sec. Pallars, leg. 1, doc. 23.

Copia certificada de 1328 , octubre 14, efectuada por Pedro Redonell notario de Ripoll.

ADM, sec. Pallars, leg. 1, doc. 23.

\section{VI}

1 de noviembre de 1242 .

Roger de Comenge, conde de Pallars, manda a los habitantes de Salàs que permanezcan en paz y se abstengan de cometer homicio alguno.

Pergamino de $140 \times 134 \mathrm{~mm}$. Buen estado de conservación. Tinta ocre. Escritura gótica.

ADM, sec. Pallars, lèg. 14, doc. 739.

Copia simple del siglo xvili.

ADM, sec. Pallars, leg. 14, doc. 739.

VII

Gerri, 12 de diciembre de 1244 . 
Roger de Comenge, conde de Pallars, dona a su hijo Arnaldo Roger el condado de Pallars.

Pergamino de $267 \times 410 \mathrm{~mm}$. Buen estado de conservación. Tinta ocre. Escritura gótica. Carta partida por ABC.

ADM, sec. Pallars, leg. 1, doc. 24. Urgel.

Copia certificada de 1276, agosto 18 efectuada por Berenguer Bord, notario de

ADM, sec. Pallars, leg. 1, doc. 24. Ripoll.

Copia certificada de 1328, octubre 14 efectuada por Pedro Redonell, notario de

ADM, sec. Pallars, leg. 1, doc. 24.

VIII

1 de septiembre de 1245.

Roger de Comenge, conde de Pallars, dona a Pedro Isern de Aron y a su mujer Maria el puig de "Penacuta" situado entre Es. taron y Aidi para su edificación y defensa.

Pergamino de $256 \times 200 \mathrm{~mm}$. Buen estado de conservación. Tinta ocre. Escritura gótica. Carta partida por ABC.

ADM, sec. Pallars, leg. 18, doc. 1.099 .

\section{IX}

6 de octubre de 1247.

Roger de Comenge, conde de Pallars, entrega en prenda a Guillermo de Orcau la batllía del castillo de Aramunt y la mitad de la renta del horno de Salàs como garantía de pago de los 270 sueldos que le había prestado.

Copia simple del siglo xIII. Pergamino de $193 \times 110 \mathrm{~mm}$. Buen estado de conservación. Tinta ocre. Escritura gótica. 
ADM, sec. Pallars, leg. 20, doc. 1.264.

Copia simple del siglo xVIII.

ADM, sec. Pallars, leg. 20, doc. 1.264.

13 de noviembre de 1247.

Roger de Comenge, conde de Pallars, otorga carta de franquicia a los habitantes de la villa de Llavorsi.

ADM, sec. Pallars, leg. 9 , doc. 340 , fols. 159r-162r.

\section{XI}

11 de julio de 1249.

Roger de Comenge, conde de Pallars, reclama a Bertrán de Aramunt la potestad de un castillo que le habia dado.

Pergamino de $177 \times 39 \mathrm{~mm}$. Buen estado de conservación. Tinta ocre. Escritura gótica. Carta partida por $\mathrm{ABC}$.

ADM, sec. Pallars, leg. 19, doc. 1.187.

$$
\text { XII }
$$

30 de agosto de 1250.

Roger de Comenge, conde de Pallars, confirma el pacto matrimonial establecido con Pedro, vizconde de Vilamur.

Pergamino de $177 \times 186 \mathrm{~mm}$. Buen estado de conservación. Tinta ocre. Escritura gótica. Carta partida por ABC.

ADM, sec. Pallars, leg. 1, doc. 25. 
14 de junio de 1253.

Roger de Comenge, conde de Pallars, dona a su hijo Ramón de Peramea el castillo y villa de Montformit.

Copia certificada de 1273, abril 15 efectuada por Bernardo Maig, canónigo y notario de Tremp. Pergamino de $220 \times 113 \mathrm{~mm}$. Buen estado de conservación. Tinta ocre. Escritura gótica.

ADM, sec. Pallars, leg. 17, doc. 1.044.

Copia simple del siglo xVI.

ADM, sec. Pallars, leg. 17, doc. 1.044.

\section{XIV}

18 de octubre de 1254.

Roger de Comenge, conde de Pallars, entrega su hijo Arnaldo Roger a Pedro, vizconde de Vilamur y varios castillos como seguridad para el cumplimiento del pacto matrimonial establecido. gótica.

Pergamino de $277 \times 64 \mathrm{~mm}$. Buen estado de conservación. Tinta ocre. Escritura

ADM, sec. Pallars, leg. 1, doc. 26.

\section{XV}

15 de mayo de 1256.

Roger de Comenge, conde de Pallars, entrega a su hijo Arnaldo Roger el condado de Pallars como heredero suyo y ruega y manda a los nobles y caballeros del condado que le obedezcan y sean fieles. 
Pergamino de $165 \times 99 \mathrm{~mm}$. Buen estado de conservación. Tinta ocre. Escritura gótica. Carta partida por ABC. Restos de cinta de cáñamo de la que penderia el sello.

ADM, sec. Paliars, leg. 1, doc. 27.

Copia simple del siglo XVIII.

ADM, sec. Pallars, leg. 1, doc. 27.

\section{XVI}

16 de mayo de 1256.

Roger de Comenge, conde de Pallars, instituye como heredero suyo a su hijo Arnaldo Roger y le entrega todo el condado de Pallars.

Pergamino de $328 \times 297 \mathrm{~mm}$. Buen estado de conservación. Tinta ocre. Escritura gótica.

ADM, sec. Pallars, leg. 1, doc. 27.

Copia certificada de 1310, marzo 17 efecutada por Bernardo de Ponts, notario de Berga.

ADM, sec. Pallars, leg. 1, doc. 27.

XVII

19 de mayo de 1256.

Roger de Comenge, conde de Pallars, instituye como heredero suyo a su hijo Arnaldo Roger y le entrega el condado de Pallars.

Copia certificada de 1310, marzo 17 efectuada por Bernardo de Ponts, notario de Berga. Pergamino de $303 \times 490 \mathrm{~mm}$. buen estado de conservación. Tinta ocre. Escritura gótica.

ADM, sec. Pallars, leg. 1, doc. 28. Ripoll.

Copia certificada de 1328, octubre 14 efectuada por Pedro Redonell, notario de 
ADM, sec. Pallars, leg. 1, doc. 28.

Copia simple del siglo XVIII.

ADM, sec. Pallars, leg. 1, doc. 28.

\section{XVIII}

21 de agosto de 1256 .

Testamento de Roger de Comenge, conde de Pallars.

Pergamino de $446 \times 353 \mathrm{~mm}$. Buen estado de conservación. Tinta ocre. Escritura gótica.

ADM, sec. Pallars, leg. 1 , doc. 30.

Copia certificada de 1302, noviembre 7 efectuada por Bernardo de Ponts, notario de Berga.

ADM, sec. Pallars, leg. 1 , doc. 30.

Copia certificada de 1310, marzo 17 efectuada por Bernardo de Ponts. notario de Berga

ADM, sec. Pallars, leg. 1, doc. 30.

Copia simple del siglo XIII mutilada.

ADM, sec. Pallars, leg. 1, doc. 30 .

$\mathrm{XIX}$.

$s / f$

Roger de Comenge, conde de Pallars, y su hijo Arnaldo Roger de una parte y Ramón de Bellera de la otra eligen como árbitros a Pedro de Berga y Roger Isern respectivamente.

Pergamino de $237 \times 237 \mathrm{~mm}$. Buen estado de conservación. Tinta ocre. Escritura gótica. Carta partida por $\mathrm{ABC}$.

ADM, sec. Pallars, leg. 16, doc. 910. 